\title{
Electrochemical Investigation on the Acid Corrosion Control of Mild Steel using Biopolymer as an Inhibitor
}

\author{
Y. Sushmitha and Padmalatha Rao* \\ Department of Chemistry, Manipal Institute of Technology, \\ Manipal Academy of Higher Education, Manipal, Karnataka, India
}

Received October 15, 2017; accepted November 2, 2018

\begin{abstract}
The present work highlights the results of the application of a green inhibitor for material conservation. The anticorrosive performance of the pectin bio-polymer was established for the corrosion control of mild steel in a $1 \mathrm{M}$ phosphoric acid medium.

Electrochemical measurements such as potentiodynamic polarization (PDP) and electrochemical impedance spectroscopy (EIS) studies were adopted for the corrosion inhibition studies.

The studies were carried out by varying the concentrations of pectin in the temperature range from $303 \mathrm{~K}$ to $318 \mathrm{~K}$. Conditions were optimized to get maximum inhibition efficiency. The surface morphology study was done by scanning electron microscope (SEM), and elemental mapping was done using energy dispersive X-ray (EDX) studies to confirm the adsorption and interaction of the inhibitor with the material.

Studies showed an increase in the inhibition efficiency with an increase in the concentration of pectin and also in the temperature. Maximum inhibition efficiency of $70 \%$ was achieved by the addition of 800 ppm of inhibitor.

Pectin acted as a mixed type inhibitor by bringing down both cathodic and anodic reactions. Kinetic and thermodynamic parameters revealed chemical adsorption of pectin onto the mild steel surface.

A suitable mechanism was proposed for the adsorption of pectin which was reaffirmed by the surface morphology studies. Pectin emerged as a potential eco-friendly green inhibitor for the corrosion control of mild steel, with economic benefits.
\end{abstract}

Keywords: mild steel; pectin; green inhibitor; electrochemical measurements; surface analysis.

\section{Introduction}

Mild steel (MS) is the one of the abundant materials found in the earth crust. It has a wide range of application in the field of chemical industries, military appliances, domestic appliances, etc. These immense applications are due to its

\footnotetext{
*Corresponding author. E-mail address: padmalatha.rao@manipal.edu
} 
easy availability, low cost and to certain properties such as high strength, malleability, ductility, etc. [1-2].

However, mild steel is highly susceptible to corrosion when in contact with corrosive media. Usually during acid pickling process, when dilute mineral acids are used, they do not only remove extraneous matter such as grease, dust, rust, etc., from the metal surface, but also lead to metal dissolution [3-5].

Even though diluted hydrochloric and sulfuric acids are preferred pickling agents, nowadays they are not industrially recommended, because of the greater degree of material loss they cause. Phosphoric acid, being mild in nature, was reported to act efficiently as a pickling agent, with minimum material loss.

In order to overcome this type of material loss, corrosion inhibitors are added to the corrosive media. Most commonly, chemical substances containing heteroatoms are used as corrosion inhibitors. Compounds containing heteroatoms such as nitrogen, sulfur, and oxygen, form a coordinate bond with the metal and create a physical barrier on its surface. This barrier prevents further metal dissolution.

However, some of these chemical compounds are reported to be toxic [6]. Toxicity may arise either during the synthesis or during application. This represents a menace both to human health and to the environment. A clean and green environment is of primary importance. Therefore, according to the environmental regulation, the use of chemical compounds as corrosion inhibitors is restricted [7].

Thus, nowadays, research is more focused towards the use of eco-friendly green inhibitors for corrosion control. Plant products, surfactants, and biopolymers are important classes of green inhibitors. Even though plant products act as excellent inhibitors, their industrial applications are highly limited.

This is mainly because of the difficulty involved in the isolation and extraction of the active components which are mainly responsible for corrosion inhibition. In addition to this, the stability of the plant products is also one of the big challenges for their continuous use [8].

Among the ecofriendly inhibitors, biopolymers are the class of compounds that contain a greater number of heteroatoms. They are readily available, non-toxic, biodegradable and capable to control metals corrosion [9]. Pectin [10] and polymeric pectates [11] were reported for the corrosion control of aluminum in an $\mathrm{HCl}$ medium.

The studies showed that the corrosion inhibition action of biopolymers is ascribed to the presence of $\mathrm{O}, \mathrm{N}, \mathrm{S}$ electron rich heteroatoms and to their larger molecular size and structure. However, to the best of our knowledge, the literature avails the use of biopolymers as inhibitors; however, there is still apprehension about the introduction of biopolymers to control aluminum corrosion in $\mathrm{HCl}$.

As a part of our work with eco-friendly corrosion inhibitors, in general, and with biopolymers, in particular [9], to control metals corrosion in various medium [12 -13], we report herein the application of pectin as an eco-friendly corrosion inhibitor for mild steel corrosion in a $\mathrm{H}_{3} \mathrm{PO}_{4}$ medium. 


\section{Experimental \\ Materials}

A MS rod with the composition (\% wt.) C (0.169), Si (0.188), Mn (0.414), P (0.0370), S (0.040), Cr (0.0200), Ni (0.0280), Mo (0.0180), Al (0.0044), Cu (0.0720) and remaining $\mathrm{Fe}$, was used for the corrosion inhibition study. Cylindrical test coupons with $1 \mathrm{~cm}^{2}$ of surface area and length of $4.5 \mathrm{~cm}$ were molded using cold setting resins. The exposed surface area of $1 \mathrm{~cm}^{2}$ was firstly polished with different grade emery paper and then by disc polisher using levigated alumina as abrasive, to get a mirror surface.

\section{Preparation of medium}

The stock solution of a higher concentration of $\mathrm{H}_{3} \mathrm{PO}_{4}$ was prepared by using $88 \% \mathrm{H}_{3} \mathrm{PO}_{4}$ (Merck) and double distilled water. It was then standardized by potentiometric titration method. The required concentration of $1 \mathrm{M} \mathrm{H}_{3} \mathrm{PO}_{4}$ was prepared by diluting it with distilled water, as and when required.

\section{Preparation of the inhibitor solution}

Pectin ( $\geq 85 \%$ esterified) from citrus peel with a molecular weight of 10 to 15 $\mathrm{kDa}$ used for the study was purchased from Sigma Aldrich. A pectin inhibitor stock solution of $1 \mathrm{~g} \mathrm{~L}^{-1}$ was prepared by dissolving $1 \mathrm{~g}$ of pectin in 1 liter of $1 \mathrm{M}$ $\mathrm{H}_{3} \mathrm{PO}_{4}$. The required concentration of pectin was prepared as and when required.

\section{Electrochemical measurements}

Electrochemical studies were carried out by using an electrochemical workstation (CH600D-series, U.S. model, CH Instruments with beta software). A conventional three-electrode Pyrex glass cell, with platinum as an auxiliary electrode, saturated calomel electrode as reference electrode and MS as working electrode was used. The mild steel specimen was polished with different grades of emery papers, and final polishing was done using disc polisher with levigated alumina as abrasive. The finely polished MS specimen was exposed to $\mathrm{H}_{3} \mathrm{PO}_{4}$. Experiments were performed under unstirred conditions, by placing the cell in a calibrated thermostat.

The system was allowed to establish a steady state open circuit potential (OCP) by immersing the electrodes in the corrosive medium for 600 seconds. The potentiodynamic polarization studies were carried out by polarizing the specimen from $-250 \mathrm{mV}$, cathodically, to $+250 \mathrm{mV}$, anodically, with respect to OCP, at the scan rate of $1 \mathrm{mV} \mathrm{s}^{-1}$, and the potentiodynamic polarization (plot of current vs. potential) plots were obtained. The impedance spectroscopy studies were carried out in the frequency range from $100 \mathrm{kHz}$ to $0.01 \mathrm{~Hz}$, at the $\mathrm{OCP}$, by applying a small amplitude AC signal of $10 \mathrm{mV}$.

PDP studies were carried out immediately after EIS studies, without any surface treatment. In each case, a minimum of 3-4 trials were done, and an average of the best three agreeing values was reported. 


\section{Scanning Electron Microscopy (SEM) and Energy-Dispersive X-ray Spectroscopy $(\mathrm{EDX})$ analysis}

The surface morphology studies of MS, in the absence and presence of the inhibitor, were done by immersing the material in the $\mathrm{H}_{3} \mathrm{PO}_{4}$ medium for $3 \mathrm{~h}$, using JEOL JSM-6380L model. Elemental mapping was performed for the same metal sample, using the energy dispersive X-ray analysis technique.

\section{Results and discussions}

\section{Electrochemical measurements}

\section{Potentiodynamic polarization (PDP) measurement}

Plots of potentiodynamic polarization studies, for mild steel corrosion in a $1 \mathrm{M}$ $\mathrm{H}_{3} \mathrm{PO}_{4}$ solution containing various concentrations of pectin, obtained by attaining open circuits potential (OCP), are illustrated in Fig. 1, and the results are shown in Table 1.
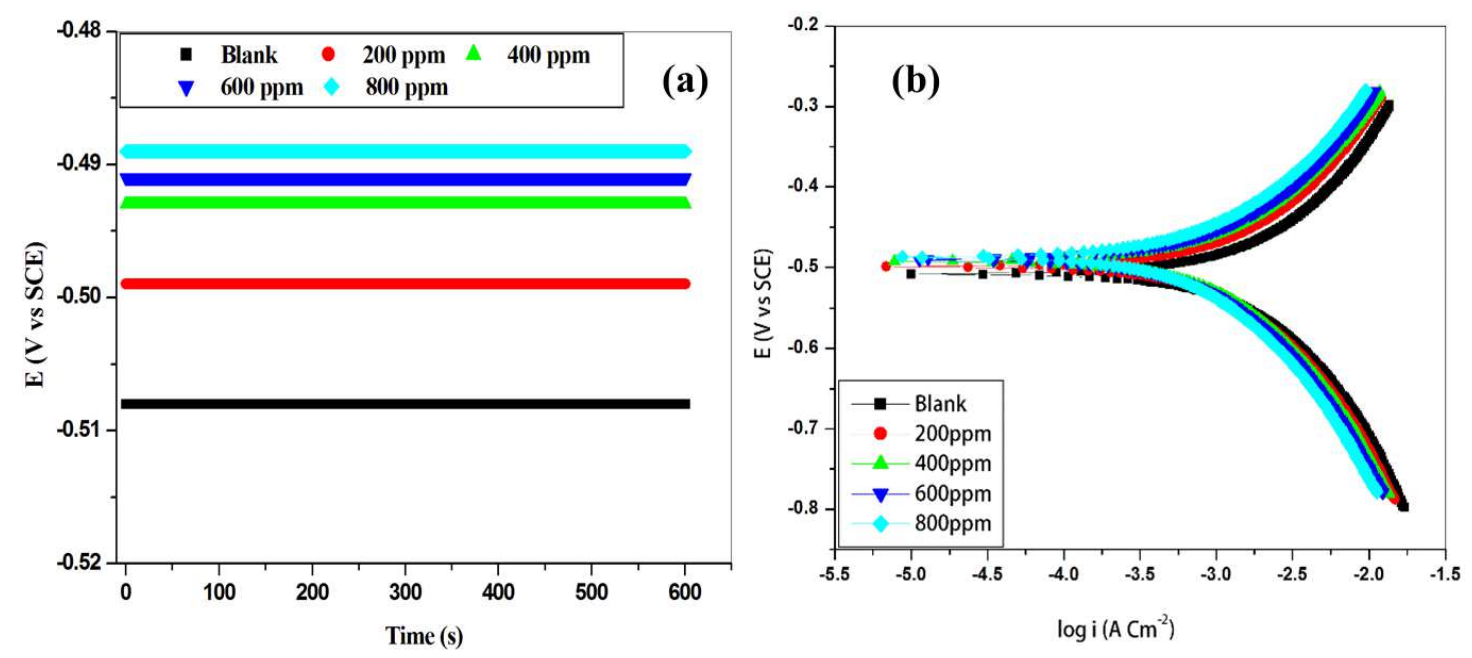

Figure 1. (a) OCP versus time plot, and (b) potentiodynamic polarization plots, for corrosion of mild steel in $\mathrm{H}_{3} \mathrm{PO}_{4}$ medium containing different concentrations of pectin at $303 \mathrm{~K}$.

Potentiodynamic polarization plots indicated active dissolution of mild steel in an acidic environment. The anticorrosive capacity of the inhibitor is also very much evident from the tabulated values. Various parameters such as corrosion potential $\left(E_{\text {corr }}\right)$, corrosion current density $\left(i_{\text {corr }}\right)$, cathodic Tafel slopes $\left(-\beta_{c}\right)$ and anodic Tafel slopes $\left(-\beta_{\mathrm{a}}\right)$ values were obtained by potentiodynamic polarization studies. By using $\mathrm{i}_{\text {corr }}$ values, the percentage inhibition efficiency [I.E $\left.(\%)\right]$ of the inhibitor was calculated [14] through equation (1):

$$
\operatorname{I.E}(\%)=\frac{i_{\operatorname{corr}(\text { blank })}-i_{\text {corr }(i n h)}}{i_{\text {corr }(\text { blank })}} \times 100
$$

Then, the corrosion rate in $\mathrm{mmy}^{-1}$ was obtained by using equation (2):

$$
\mathrm{CR}\left(\mathrm{mmy}^{-1}\right)=\frac{3270 \times M \times i_{\text {corr }}}{\rho \times \mathrm{Z}}
$$


where 3270 is a constant which reveals the unit of corrosion rate, $\rho$ is the corroding material density of mild steel, i.e., $7.725 \mathrm{~g} \mathrm{~cm}^{-3}, \mathrm{M}$ is the atomic mass of mild steel (27.925) and $\mathrm{Z}$ are the electrons transferred per metal atom (2). The corrosion current density and the corrosion potential values were obtained by the extrapolation of the cathodic and anodic slope.

Fig. 1 shows that, with an increase in pectin concentrations, the corrosion rate (CR) decreased and I.E(\%) increased. This is due to the adsorption of pectin onto the MS surface. The adsorbed inhibitor molecules block the metal surface from being attacked by the corrosive species through film formation, which results in a decrease in CR. The results are shown in Table 1.

Table 1. Results of PDP measurements for MS corrosion in a $\mathrm{H}_{3} \mathrm{PO}_{4}$ medium.

\begin{tabular}{|c|c|c|c|c|c|c|c|}
\hline $\mathbf{T}(\mathbf{K})$ & $\begin{array}{l}\text { [Pectin] } \\
\text { (ppm) }\end{array}$ & $\begin{array}{c}\text { Ecorr } \\
(\mathrm{mV} / \mathrm{SCE})\end{array}$ & $\begin{array}{c}\mathbf{i}_{\text {corr }} \times \mathbf{1 0}^{-3} \\
\left(\mathrm{~mA} \mathbf{c m}^{-2}\right)\end{array}$ & $\begin{array}{c}+\beta_{\mathrm{a}} \\
\left(\mathrm{mV} \operatorname{dec}^{-1}\right)\end{array}$ & $\begin{array}{c}-\beta_{\mathrm{c}} \\
\left(\mathrm{mV} \operatorname{dec}^{-1}\right)\end{array}$ & $\begin{array}{c}\text { CR } \\
\left(\mathrm{mmy}^{-1}\right)\end{array}$ & $\begin{array}{l}\text { I.E } \\
(\%)\end{array}$ \\
\hline \multirow{5}{*}{303} & Blank & -0.508 & 1.47 & 5.96 & 5.77 & 8.69 & - \\
\hline & 200 & -0.499 & 1.10 & 6.19 & 5.95 & 6.51 & 25.01 \\
\hline & 400 & -0.493 & 0.95 & 6.42 & 5.93 & 5.62 & 35.65 \\
\hline & 600 & -0.491 & 0.79 & 6.85 & 6.03 & 4.69 & 45.65 \\
\hline & 800 & -0.489 & 0.73 & 6.99 & 6.19 & 4.31 & 50.34 \\
\hline \multirow{5}{*}{308} & Blank & -0.507 & 1.79 & 5.68 & 5.65 & 10.57 & -- \\
\hline & 200 & -0.496 & 1.38 & 6.03 & 5.86 & 8.18 & 29.24 \\
\hline & 400 & -0.496 & 1.05 & 5.51 & 6.11 & 6.21 & 41.28 \\
\hline & 600 & -0.492 & 0.91 & 6.27 & 5.83 & 5.42 & 48.79 \\
\hline & 800 & -0.490 & 0.82 & 6.64 & 5.93 & 4.89 & 53.73 \\
\hline \multirow{5}{*}{313} & Blank & -0.507 & 1.98 & 5.57 & 5.53 & 11.68 & -- \\
\hline & 200 & -0.493 & 1.23 & 6.01 & 5.55 & 7.25 & 37.93 \\
\hline & 400 & -0.489 & 1.03 & 6.54 & 5.98 & 6.09 & 47.85 \\
\hline & 600 & -0.488 & 0.88 & 6.98 & 6.10 & 5.20 & 55.45 \\
\hline & 800 & -0.490 & 0.80 & 6.84 & 5.99 & 4.73 & 59.52 \\
\hline \multirow{5}{*}{318} & Blank & -0.507 & 2.33 & 5.35 & 5.29 & 13.81 & -- \\
\hline & 200 & -0.494 & 1.32 & 6.06 & 5.37 & 7.85 & 43.15 \\
\hline & 400 & -0.490 & 1.07 & 6.48 & 5.65 & 6.37 & 53.93 \\
\hline & 600 & -0.489 & 0.89 & 6.94 & 5.93 & 5.28 & 61.75 \\
\hline & 800 & -0.487 & 0.69 & 6.84 & 6.10 & 4.11 & 70.26 \\
\hline
\end{tabular}

As per the reported literature [15], if the displacement in $E_{\text {corr, }}$ after the inhibitor addition, is higher than $\pm 85 \mathrm{mV}$, with respect to the $E_{\text {corr }}$ of the uninhibited solution, then the inhibitor can be distinctively considered as of the cathodic or anodic type. In the present investigation, the shift in the corrosion potential is lower than $85 \mathrm{mV}$. This observation suggested that pectin acted as a mixed inhibitor.

\section{Electrochemical impedance spectroscopy (EIS) technique}

Fig. 2 represents the Nyquist plot for mild steel corrosion in a phosphoric acid medium containing different concentrations of pectin at $303 \mathrm{~K}$. Similar plots were obtained under other studied temperatures. 


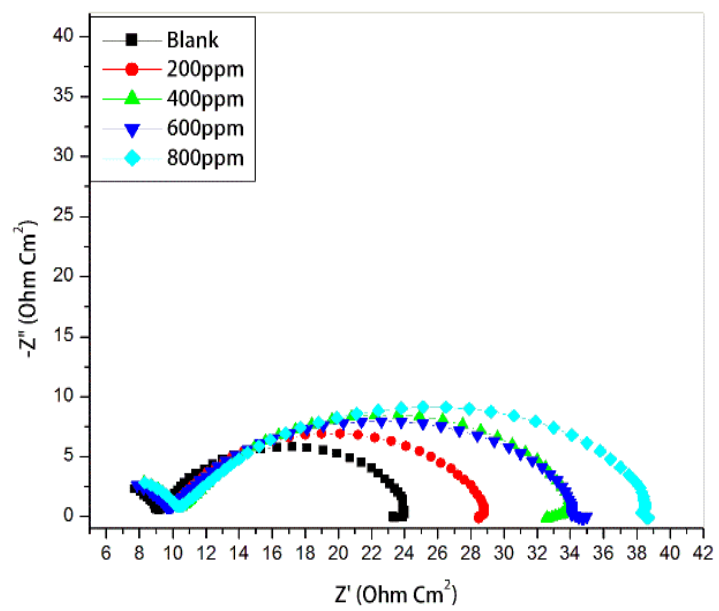

Figure 2. Nyquist plot for $\mathrm{MS}$ corrosion in $\mathrm{H}_{3} \mathrm{PO}_{4}$ medium containing different concentrations of pectin at $303 \mathrm{~K}$.

The impedance plots are semicircles, which indicates that the corrosion process is mainly charge transfer controlled. The obtained plot consisted of a capacitive loop indicating the formation of an oxide film over the metal surface. The diameter of the capacitive loop increased with an increase in pectin concentration, which suggests the hindrance of the corrosion process without any alterations to the mechanism [16].

Nyquist plot fitment was done for experimental impedance values, and an equivalent circuit consisting of nine elements was simulated using ZSimpWin software version 3.1, which are shown in Fig. 3(a) and (b), respectively.

In the equivalent circuit, $R_{s}$ is the solution resistance and $R_{c t}$ is the charge transfer resistance. $R_{L}$ and $L$ represent the inductive elements. CPE $(Q)$ is the constant phase element in parallel to the series capacitors $C_{1}, C_{2}$ and series resistors $R_{1}$, $R_{2}, R_{L}$ and $R_{c t}$. $R_{L}$ is parallel with the inductor $L$.

The double layer capacitance $\left(\mathrm{C}_{\mathrm{dl}}\right)$ was calculated from equation (3):

$$
\mathrm{C}_{\mathrm{dl}}=\mathrm{C}_{1}+\mathrm{C}_{2}
$$

Polarization resistance $\left(\mathrm{R}_{\mathrm{p}}\right)$ was calculated using equation (4):

$$
R_{p}=R_{L}+R_{t}+R_{1}+R_{2}
$$

Since polarization resistance $\left(\mathrm{R}_{\mathrm{p}}\right)$ is inversely proportional to the corrosion current, it can be used to calculate the I.E percentage using equation (5):

$$
\text { I. } E(\%)=\frac{R_{P(i n h)}-R_{P}}{R_{P(i n h)}} X 100
$$

where $\mathrm{R}_{\mathrm{p} \text { (inh.) }}$ and $\mathrm{R}_{\mathrm{p}}$ are the polarization resistances, with and without inhibitor. The electrochemical parameters obtained from circuit fitment along with the goodness of fit are given in Table 2. As evident from the table, significant pvalue is less than 0.05 and associate chi-square statistics is 0.002 . This strongly 
indicates the null rejection of no fit hypothesis, and acceptance of the goodness of fit. The measured value of polarization resistance was found to increase with the increasing concentrations of pectin, which indicated the decrease in the CR. This is in accordance with the observations obtained from PDP measurements. The decrease in $\mathrm{C}_{\mathrm{dl}}$ is because of the increase in the thickness of the electrical double layer at the metal/solution interface.
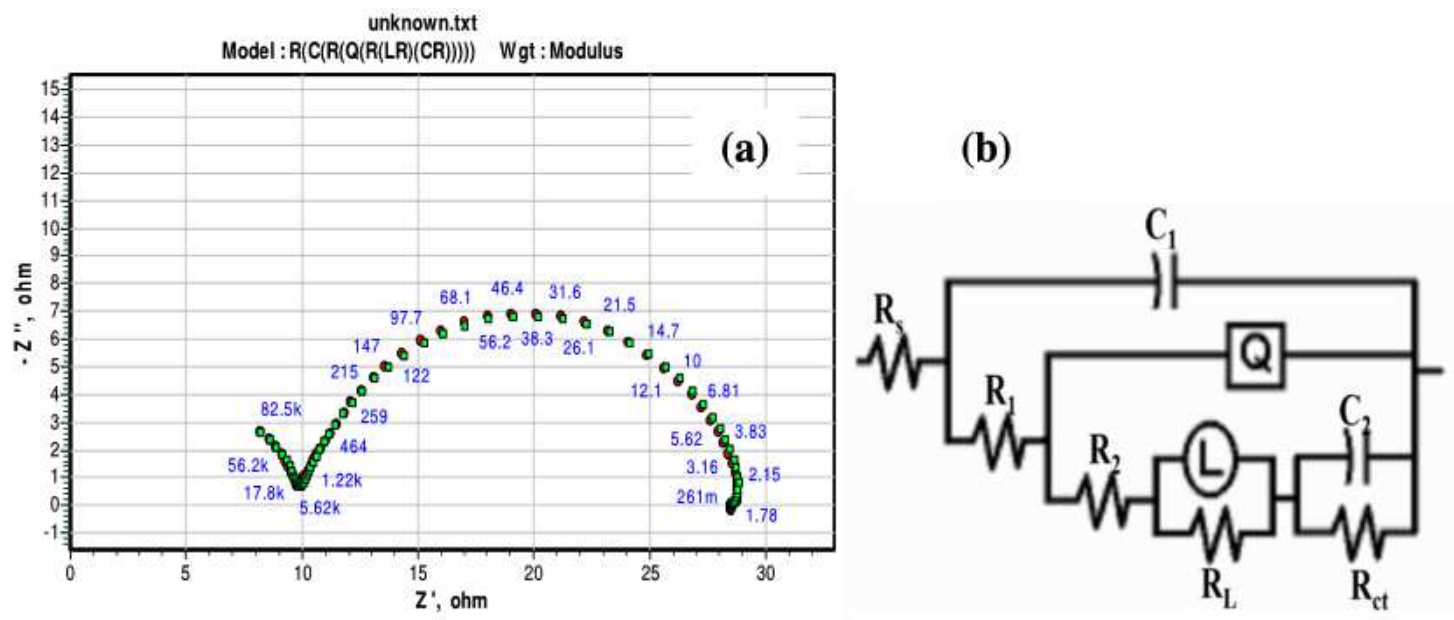

Figure 3. (a) Nyquist plot fitment for experimental EIS data for mild steel in $1 \mathrm{M}$ $\mathrm{H}_{3} \mathrm{PO}_{4}$ containing pectin. (b) Equivalent circuit.
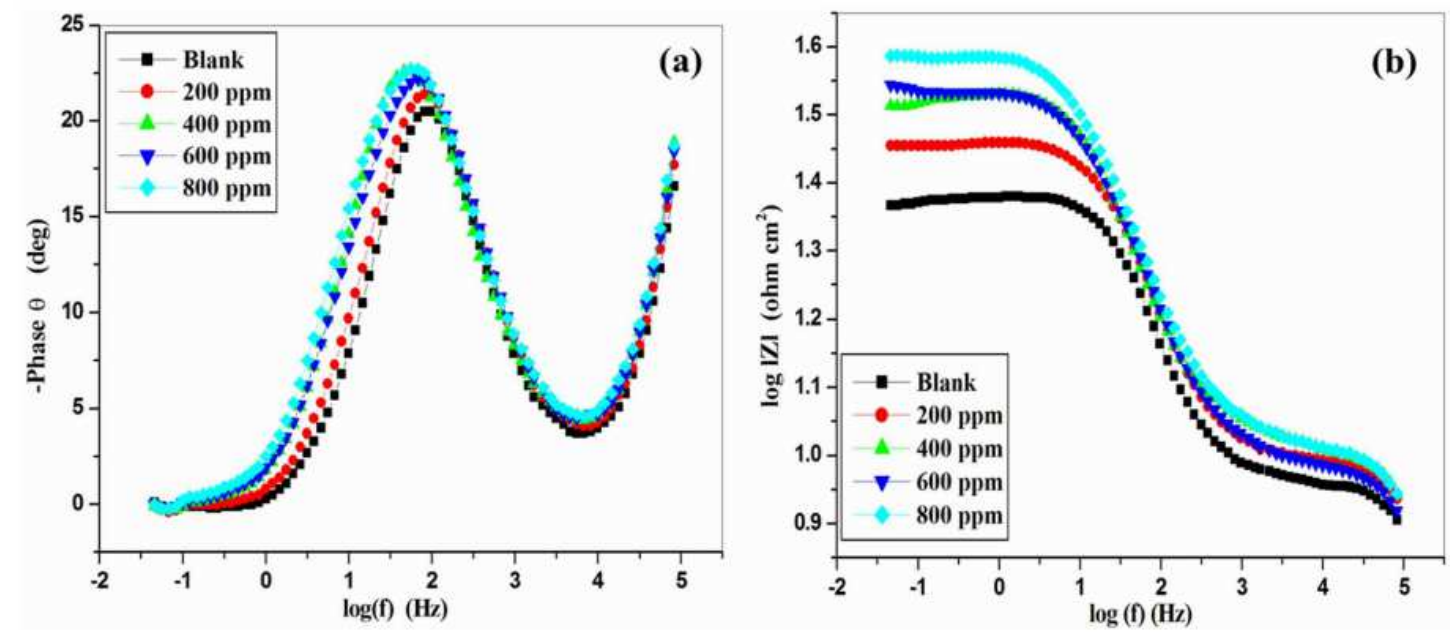

Figure 4. (a) Bode phase, and (b) Bode magnitude plots, for the corrosion of mild steel in $1 \mathrm{M} \mathrm{H}_{3} \mathrm{PO}_{4}$ at $303 \mathrm{~K}$, in the presence of various concentrations of the inhibitors.

Compared to the Nyquist plot, the Bode plot analysis is a simple one. The Bode diagram gives a clear explanation to how the electrochemical system behaves depending upon the frequency, and how it reduces the experimental data dispersion. The Bode plot is the most convenient for the extrapolation of the impedance data at LF and for its analysis. Fig. 4 shows the Bode plots obtained at OCP for mild steel, without and with various concentrations of pectin. Fig. 4a discloses that the impedance value is larger in the presence of inhibitor when compared with its absence; this observation is ascribed to decrease the CR with 
the addition of the inhibitor. Figure $4 \mathrm{~b}$ reveals the magnitude of the Bode plots of pectin. The plots showed only a single slope for both uninhibited and inhibited systems; the $R_{p}$ values were obtained from the difference between the HF limit and the LF limit in the Bode plots. These differences in the Bode plot became increasingly larger with higher concentrations of the added inhibitor.

Table 2. Impedance values obtained for corrosion of mild steel in $1 \mathrm{M} \mathrm{H}_{3} \mathrm{PO}_{4}$ containing different concentrations of pectin.

\begin{tabular}{|c|c|c|c|c|c|c|c|c|c|c|c|c|c|}
\hline $\begin{array}{c}\mathrm{T} \\
(\mathrm{K})\end{array}$ & $\begin{array}{c}{[\mathrm{Pec}]} \\
(\mathrm{ppm})\end{array}$ & $\begin{array}{c}\mathrm{R}_{\mathrm{S}} \\
\left(\boldsymbol{\Omega} \mathrm{cm}^{2}\right)\end{array}$ & $\begin{array}{c}\mathrm{R}_{1} \\
\left(\boldsymbol{\Omega} \mathrm{cm}^{2}\right)\end{array}$ & $\begin{array}{c}\mathrm{R}_{2} \\
\left(\boldsymbol{\Omega} \mathrm{cm}^{2}\right)\end{array}$ & $\begin{array}{c}\mathrm{R}_{\mathrm{ct}} \\
\left(\boldsymbol{\Omega} \mathrm{cm}^{2}\right)\end{array}$ & $\begin{array}{c}\mathrm{R}_{\mathrm{L}} \\
\left(\boldsymbol{\Omega} \mathrm{cm}^{2}\right)\end{array}$ & $\begin{array}{c}\mathrm{C}_{1} \\
\left(\mu \mathrm{F} / \mathrm{cm}^{2}\right)\end{array}$ & $\begin{array}{c}\mathrm{C}_{2} \\
\left(\mu \mathrm{F} / \mathrm{cm}^{2}\right)\end{array}$ & $\mathrm{n}$ & $\underset{\left(\mathrm{x} 10^{-3)}\right.}{\chi^{2}}$ & $\begin{array}{l}\mathrm{C}_{\mathrm{dl}} \times 10^{-6} \\
\left(\mathrm{~F} / \mathrm{cm}^{2}\right)\end{array}$ & $\begin{array}{c}\mathrm{Rp} \\
\left(\Omega \mathrm{cm}^{2}\right)\end{array}$ & $\begin{array}{l}\text { I.E } \\
(\%)\end{array}$ \\
\hline \multirow{5}{*}{303} & Blank & 0.075 & 2.57 & 1.60 & 12.72 & 1.04 & 4.45 & 13.37 & 0.99 & 2.22 & 17.82 & 17.93 & -- \\
\hline & 200 & 0.084 & 4.43 & 2.66 & 14.97 & 1.53 & 4.15 & 12.47 & 0.93 & 2.46 & 16.62 & 23.59 & 24.0 \\
\hline & 400 & 0.093 & 5.2 & 3.43 & 20.25 & 1.82 & 3.88 & 11.65 & 0.97 & 2.65 & 15.53 & 30.70 & 35.12 \\
\hline & 600 & 0.095 & 6.6 & 3.97 & 19.60 & 2.01 & 3.31 & 9.95 & 0.93 & 264 & 13.26 & 32.48 & 44.8 \\
\hline & 800 & 0.097 & 7.8 & 4.86 & 22.72 & 2.37 & 3.10 & 9.31 & 0.92 & 3.24 & 12.41 & 37.75 & 52.5 \\
\hline \multirow{5}{*}{308} & Blank & 0.068 & 1.97 & 0.94 & 5.67 & 1.00 & 5.30 & 15.9 & 0.95 & 3.86 & 21.2 & 9.58 & -- \\
\hline & 200 & 0.069 & 2.72 & 2.56 & 6.98 & 1.21 & 4.82 & 14.48 & 0.94 & 1.86 & 19.3 & 13.47 & 28.9 \\
\hline & 400 & 0.073 & 3.09 & 3.26 & 8.49 & 1.43 & 4.40 & 13.21 & 0.92 & 2.64 & 17.61 & 16.27 & 41.12 \\
\hline & 600 & 0.079 & 3.14 & 4.27 & 9.59 & 1.60 & 3.82 & 11.49 & 0.97 & 2.82 & 15.31 & 18.60 & 48.50 \\
\hline & 800 & 0.086 & 4.41 & 5.75 & 8.16 & 1.98 & 3.63 & 10.89 & 0.94 & 2.67 & 14.52 & 20.30 & 53.2 \\
\hline \multirow{5}{*}{313} & Blank & 0.064 & 1.78 & 0.83 & 4.93 & 0.95 & 7.03 & 21.12 & 0.99 & 3.24 & 28.15 & 8.495 & -- \\
\hline & 200 & 0.068 & 2.04 & 1.23 & 9.37 & 0.98 & 6.63 & 19.89 & 0.96 & 4.53 & 26.52 & 13.62 & 37.65 \\
\hline & 400 & 0.073 & 2.81 & 3.76 & 8.59 & 1.02 & 6.13 & 18.39 & 0.91 & 1.93 & 24.52 & 16.18 & 47.80 \\
\hline & 600 & 0.079 & 4.93 & 4.98 & 7.83 & 1.25 & 5.78 & 17.34 & 0.89 & 1.57 & 23.12 & 18.99 & 55.28 \\
\hline & 800 & 0.083 & 5.55 & 5.50 & 8.13 & 1.59 & 5.52 & 16.58 & 0.96 & 2.55 & 22.10 & 20.77 & 59.10 \\
\hline \multirow{5}{*}{318} & Blank & 0.059 & 1.69 & 0.68 & 4.00 & 0.73 & 8.05 & 24.16 & 0.92 & 2.27 & 32.21 & 7.10 & -- \\
\hline & 200 & 0.050 & 2.55 & 3.17 & 5.82 & 0.86 & 7.32 & 21.99 & 0.90 & 3.75 & 29.31 & 12.40 & 43.1 \\
\hline & 400 & 0.048 & 3.46 & 3.25 & 7.5 & 0.89 & 6.63 & 19.89 & 0.98 & 4.68 & 26.52 & 15.10 & 53.8 \\
\hline & 600 & 0.041 & 4.39 & 4.33 & 8.8 & 0.92 & 6.13 & 18.4 & 0.97 & 1.03 & 24.53 & 18.44 & 61.5 \\
\hline & 800 & 0.036 & 5.17 & 4.93 & 12.56 & 1.01 & 5.38 & 16.14 & 0.90 & 2.69 & 21.52 & 23.67 & 70.00 \\
\hline
\end{tabular}

The impedance plots are depressed. This depression is because of the surface inhomogeneity. Mansfeld et al. [17-18] have suggested an exponent, 'n', in the impedance function as a deviation parameter from the ideal behavior. By this suggestion, the capacitor in the equivalent circuit can be replaced by a constant phase element (CPE) that is a frequency-dependent element and related to the surface roughness.

The impedance function of CPE has the following equation:

$$
\mathrm{Z}_{\mathrm{CPE}}=1 /\left(\gamma_{\mathrm{O}} / \omega\right) \mathrm{n}
$$

where the amplitude $\gamma o$ and $n$ are frequency independent, and $\omega$ is the angular frequency for which $-\mathrm{Z}$ reaches its maximum values; $\mathrm{n}$ is dependent on the surface morphology, with values, $-1 \leq \mathrm{n} \leq 1$. $\gamma$ o and $\mathrm{n}$ can be calculated.

\section{Effect of temperature}

Inhibition efficiency of the pectin increased with an increase in temperature. This can be attributed to the increase in the protective nature of the inhibitive film formed onto the metal surface. The effect of temperature was used to calculate the energy of activation $\left(\mathrm{E}_{\mathrm{a}}\right)$ for the corrosion process, in the presence and 
absence of the inhibitor, using Arrhenius equation (7) [19], and the plot is shown in Fig. 5.

$$
\ln \mathrm{CR}=\mathrm{B}-\mathrm{Ea} / \mathrm{RT}
$$

where $\mathrm{B}$ is a constant which depends on the metal type, $\mathrm{R}$ is the universal gas constant and $\mathrm{T}$ is the absolute temperature. Plots of $\ln (\mathrm{CR})$ versus $1 / \mathrm{T}$ gave straight lines with a slope $=-\mathrm{Ea} / \mathrm{R}$.

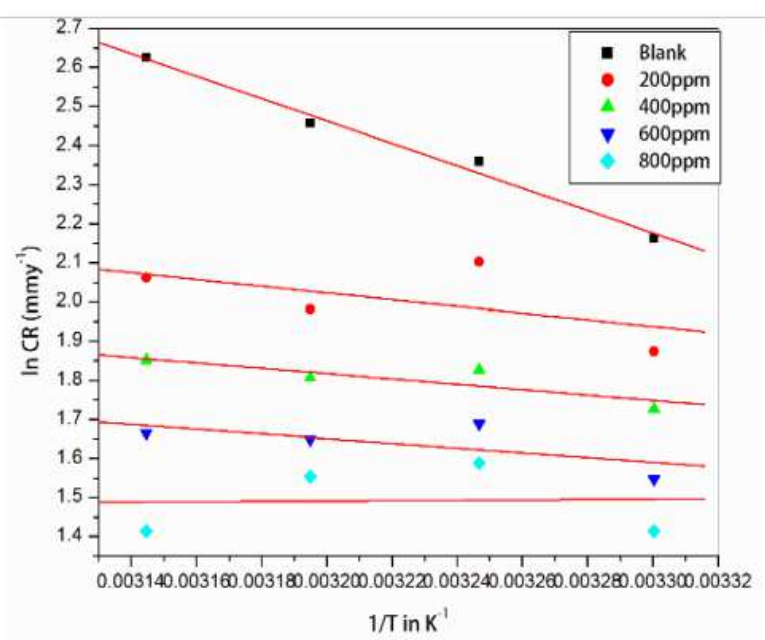

Figure 5. Plot of $\ln (\mathrm{CR})$ versus $1 / \mathrm{T}$ for corrosion of $\mathrm{MS}$ in $\mathrm{H}_{3} \mathrm{PO}_{4}$ medium.

The values of enthalpy of activation $(\Delta \mathrm{Ha})$ and entropy of activation $(\Delta \mathrm{Sa})$ for the corrosion and corrosion inhibition processes were calculated from the transition state equation [20].

$$
\mathrm{CR}=\mathrm{RT} / \mathrm{Nh} \exp \left(\Delta \mathrm{S}_{\mathrm{a}} / \mathrm{R}\right) \exp \left(-\Delta \mathrm{H}_{\mathrm{a}} / \mathrm{RT}\right)
$$

where $h$ is Planck's constant and $N$ is Avogadro's number. The plot of $\ln (\mathrm{CR} / \mathrm{T})$ versus $1 / T$ (Fig. 6) gave a collinear line with slope $=-\Delta H_{a} / R$, which gave the value of $\Delta \mathrm{H}_{\mathrm{a}}$ and intercept $=\ln (\mathrm{R} / \mathrm{Nh})+\Delta \mathrm{Sa} / \mathrm{R}$, which gave the value of $\Delta \mathrm{S}_{\mathrm{a}}$. All the activation parameters are shown in Table 3.

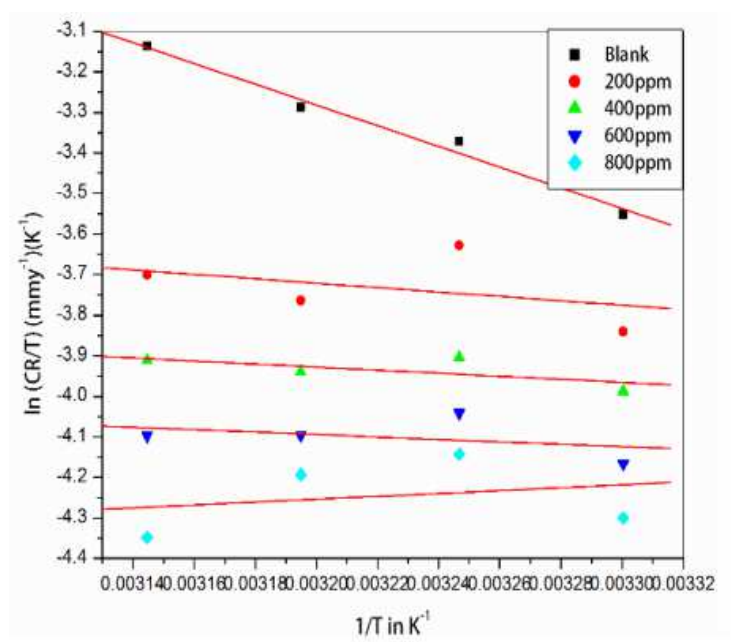

Figure 6. Plot of $\ln (\mathrm{CR} / \mathrm{T})$ versus $1 / \mathrm{T}$ for corrosion of $\mathrm{MS}$ in $\mathrm{H}_{3} \mathrm{PO}_{4}$ medium. 
Table 3. Activation parameter for corrosion of mild steel in $1 \mathrm{M} \mathrm{H}_{3} \mathrm{PO}_{4}$ containing different concentrations of pectin.

\begin{tabular}{cccc}
\hline $\begin{array}{c}{[\text { Pectin] }} \\
(\mathbf{p p m})\end{array}$ & $\begin{array}{c}\mathbf{E}_{\mathbf{a}} \\
\left(\mathbf{k J ~ m o l}^{\mathbf{- 1}}\right)\end{array}$ & $\begin{array}{c}\Delta \boldsymbol{H}_{\boldsymbol{a}} \\
\left(\mathbf{k J} \mathbf{~ m o l}^{\mathbf{1}}\right)\end{array}$ & $\begin{array}{c}\Delta \boldsymbol{S}_{\boldsymbol{a}} \\
\left(\mathbf{k J} \mathbf{~ m o l}^{\mathbf{1}}\right)\end{array}$ \\
\hline Blank & 23.86 & 21.28 & -192.62 \\
\hline $\mathbf{2 0 0}$ & 7.11 & 4.53 & -199.51 \\
\hline $\mathbf{4 0 0}$ & 5.70 & 3.12 & -200.26 \\
\hline $\mathbf{6 0 0}$ & 5.05 & 2.47 & -200.68 \\
\hline $\mathbf{8 0 0}$ & 0.39 & 2.97 & -200.50 \\
\hline
\end{tabular}

According to the literature [21], if the energy of activation $\left(E_{a}\right)$ value of the inhibitor is greater than the blank value, then it indicates physical adsorption; or else, if the $E_{a}$ value of the inhibitor is lesser than the blank value, then it indicates chemisorption.

In the present study (as in Table 3) $E_{a}$ values significantly decreased after the addition of the inhibitor. The decrease in $E_{a}$ values indicated the chemical adsorption of the pectin. The adsorbed pectin blocks the charge transfer process and thereby decreases the energy of activation value [22]. $\Delta \mathrm{H}_{\mathrm{a}}$ was approximately the same as $E_{a}$, and its value decreased after the addition of pectin. This may be due to the adsorption of the inhibitor onto the metal surface. The larger values of $\Delta \mathrm{S}_{\mathrm{a}}$ suggested a decrease in randomness ongoing from reactants towards the formation of the activated complex [23].

\section{Adsorption considerations}

The adsorption bond strength is dependent on the composition of the metal, nature and concentration of the corrosive medium, inhibitor structure and its concentration and orientation, as well as temperature. Adsorption isotherms are usually employed to explain the mechanism of interaction between an inhibitor and an adsorbent surface. This is usually achieved by fitting the degree of surface coverage data into various adsorption isotherms, and the correlation coefficients are used to determine the best-fit isotherm. In this work, the best-fitted isotherm was the Langmuir adsorption model which relates the degree of surface coverage $(\theta)$ to the concentration of pectin $\left(\mathrm{C}_{\mathrm{inh}}\right.$. $)$ according to the following equation:

$$
\frac{C}{\theta}=\frac{1}{K}+C
$$

where $K$ is the adsorption/desorption equilibrium constant $\left(\mathrm{L} \mathrm{mol}^{-1}\right)$ and $\mathrm{C}$ is the concentration of the inhibitor molecule in the electrolyte; $\theta$ is given by the following equation:

$$
\theta=\frac{I \cdot E(\%)}{100}
$$

The plot of $\frac{C}{\theta}$ versus $C$ gave a straight line; the value of $\frac{1}{K}$ was obtained from the intercept values. Then, the equilibrium constant, $\mathrm{K}$, value was obtained. This model has also been used for other inhibitor systems [24]. $\mathrm{H}_{3} \mathrm{PO}_{4}$ plots of $\mathrm{C}_{\mathrm{inh}} / \theta$ versus $C_{i n h}$ gave straight lines with the intercept (intercept $=1 / \mathrm{K}$ ). Langmuir adsorption isotherms are shown in Fig. 7. 


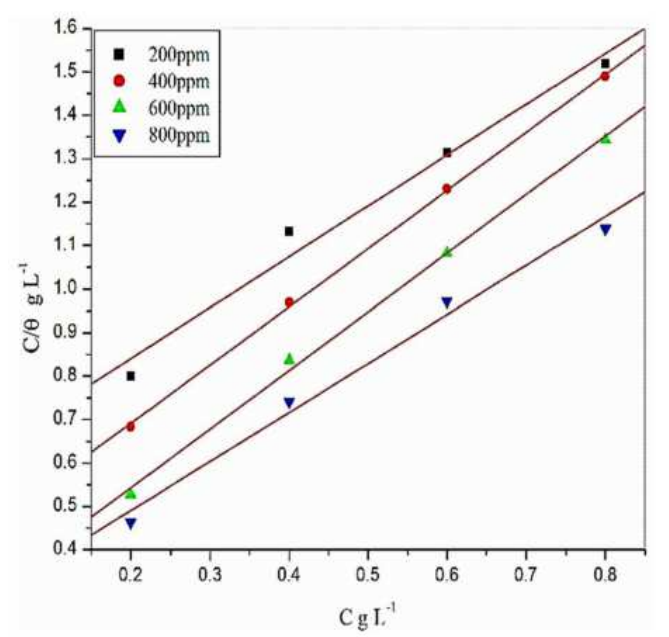

Figure 7. Langmuir adsorption isotherm for the corrosion of mild steel in $1 \mathrm{M} \mathrm{H}_{3} \mathrm{PO}_{4}$.

The correlation coefficient $\left(\mathrm{R}^{2}\right)$ was used to choose the isotherm that best fitted the experimental data. The linear regression coefficients were close to unity, and the slopes of straight lines were near unity, suggesting that the adsorption of pectin obeyed Langmuir's adsorption isotherm, and that there is a negligible interaction between the adsorbed molecules [25].

The adsorption/desorption constants $(\mathrm{K})$ are related to the standard free energy of adsorption $\left(\Delta \mathrm{G}_{\text {ads. }}^{\circ}\right)$ by the following relation:

$$
\mathrm{K}=\frac{1}{1000} \exp \left(\frac{-\Delta G^{\circ}}{R T}\right)
$$

where $\mathrm{R}$ is the universal gas constant and $\mathrm{T}$ is the absolute temperature; as the concentration of water has unit $\mathrm{gL}^{-1}$ and $\mathrm{K}$ has unit $\mathrm{Lg}^{-1}$, the value will become approximately 1000 [26].

The standard enthalpy $\left(\Delta \mathrm{H}^{\circ}\right)$ of adsorption and standard entropy of adsorption $\left(\Delta \mathrm{S}^{\mathrm{o}}\right)$ were calculated by plotting $\Delta \mathrm{G}^{\mathrm{o}}$ versus $\mathrm{T}$. This gives the linear plot, from which slope $\left(\Delta \mathrm{S}^{\circ}\right)$ and intercept $\left(\Delta \mathrm{H}^{\circ}\right)$ (the values calculated using the Gibb's Helmholtz equation) are represented in the following equation:

$$
\Delta G^{\circ}{ }_{a d s}=\Delta H^{\circ}{ }_{a d s}-T \Delta S^{\circ} \text { ads }
$$

The plot of $\Delta \mathrm{G}_{\text {ads }}^{\circ}$ versus $\mathrm{T}$ (Fig. 8) was used to calculate the standard enthalpy of adsorption ( $\Delta \mathrm{H}^{\circ}$ ads $)$ and the standard entropy of adsorption $\left(\Delta \mathrm{S}^{\circ}{ }_{\text {ads }}\right)$.

Negative values of $\Delta \mathrm{G}_{\text {ads }}^{\circ}$ suggested the spontaneous adsorption of the inhibitor onto the surface of the metal and the stability of the adsorbed layer on the MS. According to Bentiss et al., [27], if the value of $\Delta \mathrm{G}_{\text {ads }}^{\circ}$ is up to $-20 \mathrm{~kJ} \mathrm{~mol}^{-1}$, then it is considered that there is an electrostatic interaction between the protonated inhibitor species and the negatively charged metal surface, i.e., physisorption. Negative value lower than $-40 \mathrm{~kJ} \mathrm{~mol}^{-1}$ indicates sharing or transfer of electrons from the inhibitor molecule to the surface of the metal through a coordinate bond formation, i.e., chemisorption [28]. The other adsorption thermodynamic parameters such as enthalpy of adsorption $\left(\Delta \mathrm{H}^{\circ}\right.$ ads $)$ and entropy of adsorption $\left(\Delta S_{\text {ads }}^{\circ}\right)$ are obtained from the slope and intercept of the plot of $\left(\Delta \mathrm{G}_{\text {ads }}^{\circ}\right)$ versus $T$. 
In the present investigation with pectin as an inhibitor, the calculated $\Delta \mathrm{H}^{\circ}$ ads value is $47.72 \mathrm{~kJ} \mathrm{~mol}^{-1}$ in $\mathrm{H}_{3} \mathrm{PO}_{4}$ medium. This suggests that the adsorption of pectin onto the surface of MS is chemisorption. A positive value of $\Delta \mathrm{S}^{\circ}$ ads also supports chemical adsorption. The thermodynamic parameters obtained for $\mathrm{MS}$ in $\mathrm{H}_{3} \mathrm{PO}_{4}$ medium are shown in Table 4.

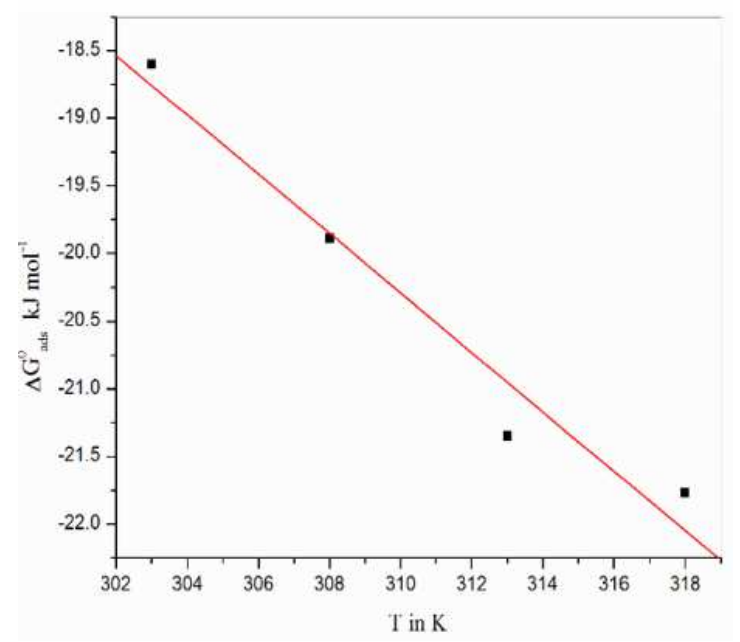

Figure 8. Plot of $\Delta \mathrm{G}_{\text {ads }}^{\circ} \mathrm{vs}$. $\mathrm{T}$ for the adsorption of pectin on mild steel in $1 \mathrm{M} \mathrm{H}_{3} \mathrm{PO}_{4}$.

Table 4. Thermodynamic parameters for the adsorption of $1 \mathrm{M} \mathrm{H}_{3} \mathrm{PO}_{4}$ containing different concentrations of pectin.

\begin{tabular}{cccc}
\hline $\begin{array}{c}\text { Temp } \\
(\mathbf{K})\end{array}$ & $\begin{array}{c}\Delta \boldsymbol{G}^{\circ}{ }_{\text {ads }} \\
\left(\mathbf{k J} \mathbf{~ m o l}^{\mathbf{1}}\right)\end{array}$ & $\begin{array}{c}\Delta \boldsymbol{H}^{\circ}{ }_{\text {ads }} \\
\left(\mathbf{k J} \mathbf{~ m o l}^{-1}\right)\end{array}$ & $\begin{array}{c}\Delta \boldsymbol{S}_{\text {ads }}^{\circ} \\
\left(\mathbf{k J ~ m o l}^{-\mathbf{1}}\right)\end{array}$ \\
\hline $\mathbf{3 0 3}$ & -18.63 & & \\
$\mathbf{3 0 8}$ & -19.885 & 47.72 & 0.2194 \\
$\mathbf{3 1 3}$ & -21.35 & & \\
$\mathbf{3 1 8}$ & -21.77 & & \\
& & &
\end{tabular}

\section{Mechanism of corrosion inhibition}

Pectin is a macromolecule containing plenty of -OH groups, as shown in Fig. 9. The donation of electrons takes place from the oxygen atom to the vacant dorbitals of MS, leading to the formation of a coordinate bond; thus, chemisorption of the pectin molecule takes place onto the metal surface. It is schematically shown in Fig. 10. The adsorbed molecules form a physical barrier between the metal and corrosive medium and prevent further dissolution of the metal.

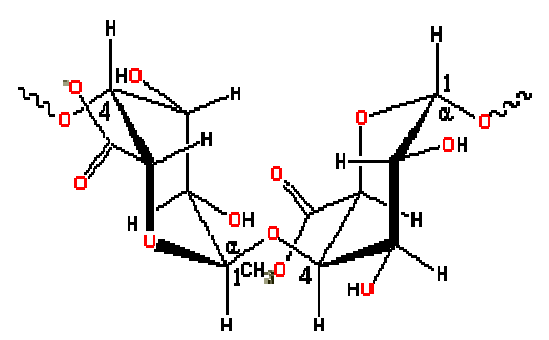

Figure 9. Structure of pectin. 


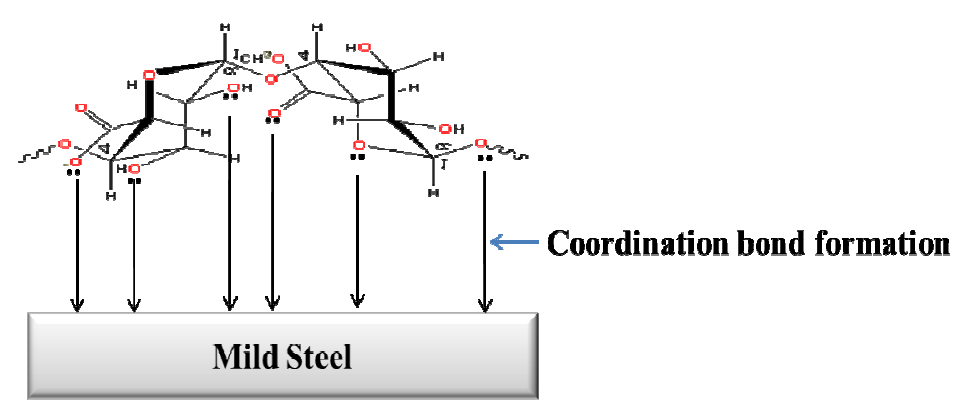

Figure 10. Mechanism of adsorption.

\section{Surface morphology studies}

Scanning Electron Microscope (SEM)

The effect of corrosion on the surface morphology of the mild steel sample was conducted by recording the SEM images of the specimen samples in the acidic medium for $3 \mathrm{~h}$, in the absence and presence of the inhibitor.

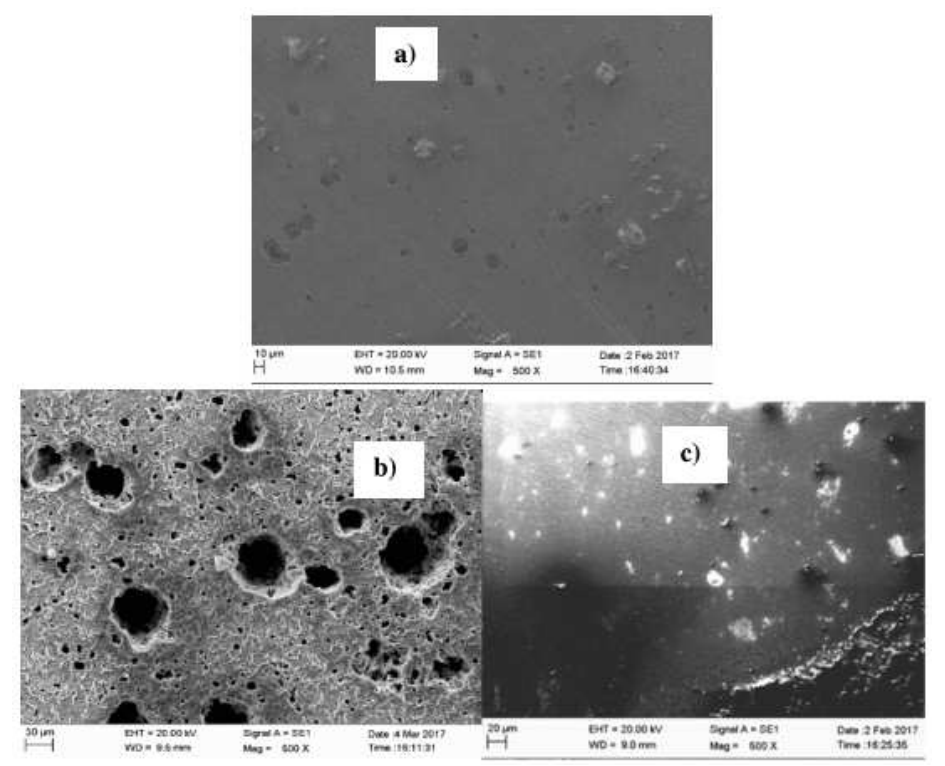

Figure 11. SEM images of (a) freshly polished mild steel surface, (b) $\mathrm{MS}+\mathrm{H}_{3} \mathrm{PO}_{4}$, and (c) $\mathrm{MS}+\mathrm{H}_{3} \mathrm{PO}_{4}+$ pectin.

The SEM images of the freshly polished MS, along with the $\mathrm{H}_{3} \mathrm{PO}_{4}$ medium and with the inhibitor are shown in Fig. 11(a)-(c). The SEM image of the freshly polished MS showed the smooth surface, whereas in the $\mathrm{H}_{3} \mathrm{PO}_{4}$ medium it showed the heterogeneous surface with large pits, which indicates that the metal undergoes pitting corrosion in the $\mathrm{H}_{3} \mathrm{PO}_{4}$ medium [17]. The SEM image of MS after the addition of pectin to the $\mathrm{H}_{3} \mathrm{PO}_{4}$ medium showed a decrease in the number of pits and an increase in the smoothness of the surface. That is due to the adsorption of pectin onto the surface of MS and to the reduction in the rate of corrosion. 


\section{Energy Dispersive X-ray analysis (EDX)}

Interaction of the corrosive medium with metal and the adsorption of the inhibitor onto the MS surface were confirmed by EDX analysis. Results are shown in Table 5. In the presence of the inhibitor, a small carbon peak is due to the adsorption of the inhibitor molecule.

Table 5. Results of EDX analysis for corrosion of MS in a $\mathrm{H}_{3} \mathrm{PO}_{4}$ medium with pectin.

\begin{tabular}{lllll}
\hline Samples & Fe & O & P & C \\
\hline Freshly polished MS & 93.4 & -- & 0.25 & 6.26 \\
MS+ H3PO4 & 56.9 & 26.72 & 10.68 & -- \\
MS+ H3PO4 +Pectin & 69.69 & 10.64 & 9.12 & 10.5 \\
\hline
\end{tabular}

\section{Conclusions}

- The inhibition efficiency of pectin increases with an increase in its concentration, and with higher temperatures.

- Pectin acted as a mixed type of inhibitor bringing both cathodic and anodic reactions under control.

- Pectin got adsorbed onto the MS surface via chemisorption, and followed Langmuir's adsorption isotherm.

- Pectin can be considered as an effective eco-friendly green inhibitor for the corrosion control of MS in the $\mathrm{H}_{3} \mathrm{PO}_{4}$ medium.

\section{Acknowledgements}

Authors acknowledge the laboratory facility provided by the Department of Chemistry, MIT, Manipal Academy of Higher Education, Manipal.

\section{References}

1. Uhlig HH, Revie RW. Corrosion and Corrosion Control, an Introduction to Corrosion Science and Engineering. New York: John Wiley \& Sons; 2003.

2. Schweitzer. Fundamentals of Corrosion, Mechanisms, Causes and Preventive Methods. New York: CRC Press; 2010.

3. Mobin M, Khan MA, Parveen M. Corros Sci. 2011;121:1558.

4. US congress, office of technology assortment. Biopolymers: making materials nature's way; 1993.

5. Sastri VS. Corrosion Inhibitors Principles and Applications. NewYork: John Wiley \& Sons; 1998.

6. Chigondo M, Chigondo F. J Chem. 2016. 1-7.

7. Rani BEA, Basu BBJ. Int J Corr. 2012. 1-15.

8. Fontana MG. Corrosion Engineering. New York: McGraw-Hill; 2005.

9. Charitha BP, Rao P. Carbohy Poly. 2017;168:337.

10. Fares MM, Maayta AK, Al-Mustafa JA. Corros Sci. 2012;60:112.

11. Hassan RM, Zaafarany IA. Materials. 2013;6:2436.

12. Charitha BP, Chenan A, Rao P. Ind Eng Chem Res. 2017;56:1137. 
13. Prabhu D, Rao P. J Mater Environ Sci. 2013;4:732-743.

14. Stupnise k-Lisac E, Gazivoda A, Madza rac M, Electrochim Acta. 2007;47:4189.

15. Sahin M, Bilgic S, Yilmaz H. Appl Surf Sci. 2003;195:1.

16. Aytac A, Ozmen U, Kabasakaloglu M. Mater Chem Phys. 2005;89:176.

17. Mansfeld F, Lin S, Kim K, et al. Corros Sci. 1987;27:997.

18. Mansfeld F, Lin S, Kim K, et al. Mater Corros. 1988;39:487.

19. Bessone JB, Salinas DR, Mayer CE, et al. J Electrochim Acta. 1992;37:2283.

20. Umoren SA, Obot IB, Ebenso EE, et al. Anti-Corros Meth Mater. 2006;53:277.

21. Shivakumar SS, Mohana KN. J Mat Environ Sci. 2013;4:44.

22. Ameer MA, Khamis E, Al-Senani G. J Appl Electrochem. 2002;32:149.

23. Bouklah M, Hammouti B, Lagrenee M, et al. Corros Sci. 2006;48:2831.

24. Ameer MA, Khamis E, Al-Senani G. J Appl Electrochem. 2002;32:149.

25. Mobin M, Khan MA, Parveen M. Corros Sci. 2011;121:1558.

26. Li X, Deng S. Corros Sci. 2012;65:299.

27. Bentiss F, Traisnel M, Lagrenee M. J Appl Electrochem. 2001;31:41.

28. Foad El Sherbini EE. Mater Chem Phys. 1990;60:286. 